\title{
Ethos e vozeamentos
}

\author{
Fernanda Santana Gomes*
}

\begin{abstract}
Resumo
O estudo consiste em uma análise discursiva da música "Carta à mãe África”, de Genival Oliveira Gonçalves. Com proeminente teor crítico social, o discurso remete ao racismo, de ontem e hoje, e à escravidão do negro ocorrida no passado do Brasil, mas que no presente ainda deixa transparecer marcas de opressão e violação dos direitos humanos. O principal objetivo é examinar como se constitui o ethos discursivo do enunciador. Dessa forma, busca-se flagrar os aspectos linguístico-discursivos do texto como interdiscursividade, processos de metaforização, jogos antitéticos e semióticos, responsividade discursiva, ativação de auditórios e construção, mobilização e projeção do ethos discursivo. O estudo baseiase, principalmente, nas concepções teóricas de Bakhtin (2002, 2003, 2014) sobre dialogismo e polifonia e nas noções de ethos cunhadas por Aristóteles (2015) e Maingueneau (2008a, 2008b). Procedendo à análise, tornou-se possível perceber a atividade discursiva do enunciador, observar como se posiciona enunciativamente, instaurando e articulando movimentos dialógicos, a fim de mobilizar o auditório e legitimar o seu discurso. Sendo assim, foi possível perceber como se dá a construção e projeção do seu ethos discursivo.

Palavras-chave: Ethos. Dialogismo. Polifonia. Alteridade. Responsividade discursiva.
\end{abstract}

* Pontifícia Universidade Católica de Minas Gerais (PUC Minas). Doutoranda em Linguística e Língua Portuguesa Gomes (Bolsista CAPES). ORCID https://orcid.org/0000-0003-2758-7369.

Cadernos CESPUC de Pesquisa. Série Ensaios. n.37, $2^{\circ}$ Sem./2020, p. 45-65. e-ISSN: 2358-3231 (OJS). Recebido em: 07/08/2020. Aceito em: 19/10/2020. 


\title{
Ethos And Voices
}

\author{
Fernanda Santana Gomes
}

\begin{abstract}
The study consists of a discursive analysis of the song "Carta à mãe África ", by Genival Oliveira Gonçalves. With a prominent social criticism, the discourse refers to the racism of yesterday and today and to the slavery of the black population that happened in the past of Brazil, but which at present still shows its marks of oppression and violation of human rights. The main objective is to examine how the discursive ethos of the enunciator is constituted. It seeks to capture the linguistic-discursive aspects of the text such as interdiscursivity, processes of metaphorization, antithetical and semiotic games, discursive responsiveness, construction, mobilization and projection of the discursive ethos. The study is based mainly on Bakhtin's $(2002,2003,2014)$ theoretical conceptions about dialogism and polyphony and on the notions of ethos coined by Aristotle (2015) and Maingueneau (2008a, 2008b). Proceeding to the analysis, it became possible to perceive the discursive activity of the enunciator, to observe how he positions him enunciatively, establishing and articulating dialogical movements, in order to mobilize the audience and to legitimize his discourse. Thus, it was possible to perceive how the construction and projection of his discursive ethos takes place.
\end{abstract}

Keywords: Ethos. Dialogism. Polyphony. Alterity. Discursive responsiveness. 


\section{Introdução}

Quando se escreve, a alteridade se impõe, inconscientemente, à linearidade discursiva instituída (AGUSTINI; GRIGOLETTO, 2008, p. 147).

Toda palavra comporta duas faces - procede de alguém e se dirige para alguém. Ela não é determinada pelo significado e nem pelo significante. Ela serve de ponte entre locutor e interlocutor, propiciando a interpretação e a compreensão da vida humana. É no curso da interação verbal que a palavra é concebida como um signo ideológico (BAKHTIN, 2003, 2014). Conforme o seu contexto de origem, a palavra ganha diferentes significados. Visto isso, a palavra acaba se tornando um lócus em que valores fundamentais de uma dada sociedade se explicitam e se confrontam. Sendo assim, o tecido textual propõe e convoca o locutor e o interlocutor a problematizarem o contexto social ora idealizado e construído pela sociedade, assim como a ordem estabelecida.

A noção de dialogismo implica essa existência da relação eu-tu, sempre permeada e interpelada pelos signos linguísticos. Conforme Bakhtin (2003, 2014) argumenta, é na relação com a alteridade que os sujeitos vão se constituindo. Nesse sentido, ao se constituir, por conseguinte, ele também se altera. No entanto, somente se consolida socialmente por meio das palavras, dos signos, especialmente devido às interações. A palavra, portanto, projeta-se como indicador das transformações sociais, refletindo e refratando a nossa constituição intersubjetiva.

Nos nossos atos de interpretação e compreensão, a palavra alheia se faz sempre presente. O outro é elemento central para a nossa (trans)formação. $\mathrm{Na}$ filosofia de Bakhtin, a noção de alteridade se relaciona diretamente com as noções de pluralidade, heteroglossia e polissemia, imbricadas pela(s) ideologia(s). E é justamente a alteridade que fundamenta a identidade do sujeito, a qual se desenvolve por meio das relações dialógicas e valorativas com outros sujeitos, com diferentes opiniões, perspectivas e consciências.

Tendo como referências centrais as concepções teóricas de Bakhtin $(2002,2003,2014)$ a respeito de dialogismo e polifonia e as noções de ethos cunhadas por Aristóteles (2015) e Maingueneau (2008a, 2008b), procedo à análise do discurso da música "Carta à mãe África" (objeto analítico deste 
estudo - vide seção 3), com o objetivo de examinar as marcas do trabalho do enunciador na escrita. Para tanto, busco flagrar, no corpus de análise, os aspectos constitutivos do sentido do texto, os recursos de articulação adotados e as estratégias implementadas pelo enunciador, considerando os movimentos dialógicos (atividades de contrapalavra), a interdiscursividade, os deslocamentos/deslizamentos (processos de metaforização, jogos antitéticos e semióticos), a historicidade discursiva, a ativação de auditórios e a construção e projeção de imagem do enunciador - o ethos discursivo.

Vozes bem marcantes e intensas perpassam pelo plano discursivo da música "Carta à mãe África", destacando-se, sobretudo, a voz do sujeito marginalizado, vítima de práticas de depreciação, desvalorização, estigmatização, opressão e silenciamento e a voz do sujeito resiliente, em estado permanente de luta, de validação de sua dignidade e valorização das tradições socioculturais que o constitui e o legitima. No tecido discursivo do corpus analítico, percebe-se um sujeito em estado de dispersão que toma posições, revelando-se atravessado e interpelado pelas injunções históricas, políticas, sociais e culturais (FOUCAULT, 1996). É por meio do discurso e sob esse movimento de interação que o ethos vai se construindo, posto que é uma noção discursiva (MAINGUENEAU, 2008b). No processo de tessitura textual da música é mobilizado e projetado um ethos cindido, interpelado, incompleto e poroso - o ethos do lutador - que dá vida às vozes que reverberam a resiliência ${ }^{1}$ da população negra frente ao discurso do racismo.

Propiciar discussões sobre o discurso do racismo, em especial no que tange à população negra, é indispensável, com vistas a confrontar os discursos de ódio que são propagados de forma recorrente em nossa sociedade, os quais geram e reproduzem posturas e comportamentos que reforçam a marginalização e a opressão dos sujeitos/povos/nações, o silenciamento de suas vozes e a ocultação de suas práticas socioculturais.

\footnotetext{
1 "Resiliência é uma capacidade universal que permite que uma pessoa, grupo ou comunidade previna, minimize ou supere os efeitos nocivos das adversidades" (GROTBERG, 1995, p. 7). Essa é a definição adotada pelo Projeto Internacional de Resiliência, coordenado por Edith Grotberg e apoiado pela Bernard van Leer Foundation (Cf.: GROTBERG, E. A guide to promoting resilience in children: strengthening the human spirit. The Hague: The Bernard van Leer Foundation, 1995). Resilio (latim) significa retornar a um estado anterior. O termo originou-se nos âmbitos da física e da engenharia. Um dos precursores da ideia de resiliência foi Thomas Yang, cientista inglês que propôs o conceito de "módulo de elasticidade" (1807), após realizar experimentos com tensão e compressão de barras. Na área da física, o termo descreve a capacidade que um corpo físico tem de voltar ao normal, após ter sofrido pressão sobre si. Refere-se, pois a uma energia de deformação máxima que um corpo é capaz de armazenar, sem sofrer deformações permanentes. Já nas ciências humanas, a resiliência é abordada como a capacidade humana de reconstrução positiva perante as adversidades (GOLDSTEIN, 2012).
} 


\section{Dialogismo e polifonia: relações de intersubjetividade}

A noção de interação vinculada à função constitutiva da linguagem é preconizada por Bakhtin $(2003$, 2014) pela compreensão de uma língua concreta fundamentada na enunciação. Trata-se do uso da língua na dinâmica da responsividade e das relações dialógicas nas esferas e manifestações da atividade humana. Diferentemente de um sistema abstrato (objetivo e homogêneo) de formas, com um centro subjetivo-psicológico de enunciação (o do eu), Bakhtin concebe a língua como atividade humana constituída na interação trabalhada na e pela relação dialógica estabelecida entre o eu e o outrem. O conceito de diálogo como condição de linguagem decorre dessa compreensão, sobretudo a partir do caráter ontológico que circunscreve as práticas linguísticas humanas. Esse diálogo é entendido no sentido mais amplo, pois envolve a língua, os interlocutores e o contexto sócio-histórico e ideológico de produção de enunciados.

Sob essa ótica, a enunciação consiste em um produto da interação social, no tocante a um ato de fala determinado pela situação imediata ou pelo contexto mais abrangente de uma dada comunidade linguística. Essa relação propicia movimentos de intersubjetividade. Na posição de locutor, o sujeito interage com o outrem, buscando atuar sobre ele, promover a concordância e a aceitação do dito e a realização, quando suscitada, do que se propõe. Nesse percurso, são percebidos os efeitos de sentido do discurso e o processo de compreensão ativa e responsiva, como réplicas, que implicam uma reação/resposta do interlocutor.

Consideradas essas concepções, cabe destacar que Bakhtin (2003, 2014) demonstra uma crítica epistemológica bastante acentuada em relação às oposições entre elementos subjetivos (aqueles encontrados na consciência humana) e elementos objetivos (aqueles vivenciados no mundo real) da teoria de Saussure. Para o autor, tais elementos não alcançam o verdadeiro núcleo da realidade linguística - a comunicação, que somente ganha status de completude por meio da interação verbal. É nessa linha de pensamento que Bakhtin (2014) aponta a emergência de uma abordagem marxista da linguagem, relevando a relação entre linguagem e sociedade, com a pretensão de questionar a dialética do signo enquanto efeito das estruturas sociais. 
A concepção de linguagem bakhtiniana, compreendida como processo de interação social, fundamenta-se, portanto, nos seguintes princípios: (a) no diálogo com o outro, sendo o sujeito social, histórico e ideologicamente situado, constituído na interação verbal; (b) na noção de que a linguagem é heterogênea, marcada pela presença do outro, havendo a manifestação dos papéis sociais e da(s) posição(ões) dos interlocutores, de suas imagens diante de outros interlocutores e da sociedade; e (c) na questão da discursividade, seja ela simples ou complexa (BAKHTIN, 2003).

Contrapondo a ideia de que o homem seja um mero objeto, os postulados de Bakhtin deixam entrever que se deve construir a imagem do homem numa comunicação interativa. Para que possamos nos reconhecer, precisamos do outro. Conhecemo-nos por meio do outro. Nesse sentido, há uma projeção no outro e o outro se projeta em nós - intenso movimento de reflexões e refrações. Nesse percurso, a polifonia reside justamente no fato de que o eu não se concebe sem o outro. Na polifonia, o dialogismo se deixa ver por meio de muitas vozes polêmicas. Em contrapartida, na monofonia, há somente o dialogismo, o qual é constitutivo da linguagem, posto que o diálogo é, de certa forma, mascarado e apenas uma voz se faz ouvir, sendo as outras vozes veladas, marginalizadas, preteridas. Portanto, há uma distinção bem demarcada entre a polifonia (dialogismo polifônico) e a dialogia (monofonia ou dialogismo monofônico) (BAKHTIN, 2002, 2003, 2014).

A essência da polifonia estáintrinsecamente correlacionada à posição do enunciador como aquele que rege uma orquestra composta pelas variadas vozes que constituem o processo dialógico. O enunciador é o responsável por criar as condições para que haja a manifestação do conjunto de vozes que converge sobre si mesmo. Essas vozes e consciências são sujeitos de seus próprios discursos, deixando transparecer independência e se relacionando com as diversas outras vozes no tecido discursivo. A polifonia consiste, pois, na multiplicidade de vozes e pensamentos independentes que exercem influência na interação do sujeito (BAKHTIN, 2002). Assim, "[...] pode-se dizer que o homem tem uma necessidade estética absoluta do outro, do seu ativismo que vê, lembra-se, reúne e unifica que é o único capaz de criar para 
ele uma personalidade externamente acabada; tal personalidade não existe se o outro não a cria [...]" (BAKHTIN, 2003, p. 33)2.

Estabelecendo essa associação do outro a si mesmo, o sujeito demonstra proatividade, conseguindo refletir-se nessa alteridade. $\mathrm{O}$ dialogismo bakhtiniano possibilita que o sujeito se realize por meio da sua palavra, assim como pelas palavras dos outros. Ademais, é importante entender que o sentido da enunciação não se encontra no sujeito, tampouco na palavra e nos interlocutores, ele é o efeito da interação entre os sujeitos, produzido por meio de signos linguísticos.

Dada a compreensão ativa, apreendemos o sentido. $O$ ato de compreender remete a opor à palavra do locutor uma contrapalavra. A noção de compreensão ativa preconizada por Bakhtin $(2002,2003)$ elucida o movimento dialógico da enunciação. O locutor enuncia em função da existência, seja real ou virtual, de um interlocutor, demandando deste uma atitude responsiva, com antecipação sobre aquilo que o outro visa a colocar, fato que o faz vivenciar ou projetar a posição de seu ouvinte. Como destaca Bakhtin (2014), todo discurso é orientado para a resposta, não podendo evitar a expressiva influência do discurso da resposta antecipada, posto que sempre haverá comentários sobre ele e a ele dirigidos.

Compreendemos a enunciação à medida que a colocamos no movimento dialógico dos enunciados, defrontando-a com os nossos dizeres, assim como com os dizeres alheios. A compreensão dos enunciados de outrem ocorre quando as palavras provocam ressonâncias ideológicas. É devido à dialética interna constitutiva do signo que o sujeito se reflete e se refrata na linguagem. Por vezes, a palavra representa, deixa entrever o resultado polêmico de um embate social (BAKHTIN, 2002, 2003). Consoante essa concepção, pode-se dizer que a palavra mantém um movimento que se volta para o exterior, para a alteridade, para o discurso do outro - é função da dinâmica dialógica demandada pela ordem da linguagem. Explicitados esses aspectos, entende-se que o dialogismo na/da linguagem é, efetivamente, condição estruturante da palavra.

Sob a perspectiva da teoria bakhtiniana, toda relação dialógica questiona o monologismo e problematiza a palavra de outrem. Cumpre

\footnotetext{
2 Para Bakhtin (2002), o gênero romance apresenta diferentes vozes sociais, as quais se defrontam e manifestam variados pontos de vista sociais no tocante a um dado objeto. Sendo assim, consiste em um gênero polifônico por natureza. Para exemplificar, Bakhtin aponta o romance polifônico de Dostoiévski. De acordo com Bakhtin (2002, p. 4), "a multiplicidade de vozes e consciências independentes e imiscíveis e a autêntica polifonia de vozes plenivalentes constituem, de fato, a peculiaridade fundamental dos romances de Dostoiévski".
} 
sublinhar também que as relações dialógicas são capazes de, discursivamente, revelar/colocar em cena o que Bakhtin (2002, 2003) concebe por arquitetônica (ético-estética) da palavra, isto é, a relação valorativa das posições-sujeito "eu para mim", "eu para o outro" e "outro para mim".

Nesse contexto permeado pelo princípio da interação, importa para Bakhtin a heterogeneidade constitutiva, posto que é entre discursos. Há de se pontuar que a sua apreensão é devida à memória discursiva de uma dada formação social. Segundo Indursky (2011), a memória discursiva é substancialmente da ordem ideológica e, sob uma determinada formação discursiva, é capaz de refletir o entrecruzamento de sentidos da memória mítica e da memória social, demonstrando-se ativa, com sentidos deslizantes e variáveis. Para produzir gestos de interpretação no texto e se inscrever na sua discursividade, buscando significar, o sujeito precisa resgatar a memória discursiva. Isso porque o discurso não se desenvolve sem memória, assim como a linguagem não tem significado sem a história, posto que, como salienta Courtine (2006), a linguagem é o tecido da memória.

Quando o sujeito se inscreve na prática da escrita, ele se vê imerso em um movimento pendular, oscilando entre singularidade e alteridade. Isso porque, "a escrita consiste em um tecer e retecer de fragmentos de discursos outros. Ela trabalha com o simbólico e produz um espaço simbólico, em que diferentes vozes anônimas (ou não) ecoam, se entrelaçam e, mesmo, por vezes, se contradizem" (INDURSKY, 2016, p. 35). Nesse sentido, a escrita pressupõe a singularidade do sujeito e a determinação do outro: o lugar que o sujeito ocupa socialmente, e, também, o lugar que o seu leitor ocupa, as condições de produção da sua escrita, entre outros aspectos - o que acaba produzindo um efeito ideológico (AGUSTINI; GRIGOLETTO, 2008). Dessa forma, essas autoras ressaltam que:

O sujeito busca, sobretudo na escrita de si, uma maneira de construir sua identidade, através da memória e das relações de identificação com o outro, num constante movimento entre a singularidade e a alteridade. Ou seja, segundo Rickes (2002), a escrita faz trabalhar a falta que é constitutiva do sujeito. Mas, ao apagar a falta, o sujeito não faz outra coisa senão revelá-la, através de um gesto que é singular (AGUSTINI; GRIGOLETTO, 2008, p. 146). 
$\mathrm{Na}$ análise discursiva proposta neste estudo, o corpus tomado como objeto analítico apresenta-nos um ethos (a ser explorado detidamente na seção 3) sob o prisma da resiliência, o qual é projetado discursivamente devido aos movimentos dialógicos, à dinâmica da alteridade e aos vozeamentos que perpassam e constituem o discurso e, concomitantemente, o sujeito (enunciador). Sendo assim, na seção subsequente será desenvolvida a noção de ethos, sob as perspectivas de Aristóteles (2015) e Maingueneau (2008a, 200b), com vistas à percepção e à compreensão de como se dá a construção, mobilização e projeção do ethos discursivo em "Carta à Mãe África”.

\section{O ethos na esfera social}

Conforme os preceitos aristotélicos, o discurso engendra três provas - ethos, logos e pathos, as quais consistem em qualidades que o orador deve demonstrar ao proferir um discurso. Sendo assim, no plano enunciativo, a persuasão pode ser garantida pelo caráter (ethos), pela disposição do auditório ao sentir emoção (pathos) e pelo discurso em si (logos).

$\mathrm{Na}$ concepção de Aristóteles (2015), o ethos constitui a mais importante das três provas produzidas pelo discurso e está diretamente ligado à Retórica, em que o orador, no ato de sua fala, visa à construção de uma imagem positiva de si mesmo a fim de persuadir o seu auditório. $\mathrm{Na}$ Retórica, o ethos pode ser considerado como uma característica individual e peculiar de um orador em uma determinada situação oratória e sempre é construído na instância do discurso.

Sob a perspectiva de Maingueneau (2008b), o ethos é concebido como uma categoria que resulta da interação de determinados fatores, como: ethos pré-discursivo, ethos discursivo (ethos mostrado) e, também, de fragmentos textuais em que o enunciador evoca sua própria enunciação (ethos dito), seja diretamente ou indiretamente (metáforas ou alusões a outras cenas de fala). Para o autor, o ethos está prontamente ligado ao estatuto do locutor, à questão de sua legitimidade, ou seja, ao processo de sua legitimação pela fala, isso porque a maneira de dizer pode autorizar a construção de uma verdadeira imagem de si. 
À medida que afirma que o ethos é a imagem de si no discurso, Maingueneau (2008b) retoma o conceito de ethos preconizado por Aristóteles. No entanto, cabe ressaltar que ele acaba ampliando e reformulando esse conceito aristotélico. Sua pretensão era analisar imagens criadas pelos enunciados nos discursos tanto orais quanto escritos, não se restringindo apenas à eloquência, à oralidade em situação de fala, assim como preconizava a Retórica Clássica, a qual primava também pelo aspecto físico do orador, pelos seus gestos e sua entonação.

Compreende-se, portanto, que o conceito de ethos da Retórica aristotélica passa por uma ressignificação no campo da Análise do Discurso por Maingueneau. $\mathrm{O}$ autor caracteriza o ethos como sendo ligado não apenas pela dimensão verbal. Maingueneau (2008b) entende o conceito de ethos como uma noção discursiva (sua construção se dá por meio do discurso) e para além de seu aspecto persuasivo, considerando-o como um processo que permite refletir a respeito da adesão do auditório a determinado posicionamento, sendo valorizado o processo interativo entre orador/locutor e auditório/destinatário.

Assim como Aristóteles preconizava, o ethos, para Maingueneau (2008b), é construído no âmbito da atividade discursiva, sendo desconsiderada, portanto, a ideia do ethos pré-estabelecido. Dessa forma, pode-se depreender que a construção da imagem de si na instância enunciativa só se efetiva quando o enunciador, ao tomar a palavra, consegue se apresentar, se expor ao seu interlocutor no desencadeamento de seu discurso. No tocante à eficácia do ethos, o autor pontua que ela está vinculada ao ato/processo de enunciação. Ademais, ele não ignora o fato de que o público-alvo (o auditório) constrói também representações do ethos do enunciador antes mesmo que ele as projete (MAINGUENEAU, 2008b).

$\mathrm{O}$ ethos demanda uma experiência sensível do discurso, dado que visa a mobilizar a afetividade do destinatário. Dessa forma, em busca da compreensão do ethos, é necessário que a interpretação dos enunciados não seja reduzida a apenas uma simples decodificação, mas que se perceba a influência da experiência sensível que é posta na comunicação verbal. Quando da existência de um ethos envolvente e atuante na teia discursiva, o coenunciador ultrapassa o exercício de decifração de conteúdos para participar do mundo concebido pela enunciação, por vezes compartilhando $\mathrm{da}(\mathrm{s})$ identidade(s) que transitam e/ou fundamentam o discurso. As ideias 
acabam promovendo um movimento de adesão devido à maneira de dizer que reflete também a maneira de ser. O poder persuasivo de um discurso conduz o destinatário à identificação com o movimento de um corpo, seja esquemático ou investido de valores (MAINGUENEAU, 2008a).

Sob essa ótica, os conteúdos seriam dependentes da cena de enunciação. Nesse sentido, portanto, afastamo-nos de uma concepção do discurso voltada basicamente a noções como procedimento e/ou estratégia. Assim como Maingueneau (2008a, p. 29) destaca, "a adesão do destinatário se opera por um escoramento recíproco entre a cena de enunciação, da qual o ethos participa, e o conteúdo nela desdobrado".

Na seção seguinte, será desencadeada a análise discursiva da música "Carta à Mãe África", em que os vozeamentos (imersos no movimento de interação) propiciam a constituição do auditório, a responsividade discursiva ativa e a construção e projeção do ethos discursivo.

\section{Construção e projeção do ethos}

A música "Carta à mãe África", de Genival Oliveira Gonçalves, mais conhecido como GOG - o poeta, rapper e escritor brasileiro, consiste em um discurso que retrata o racismo na carne viva, perpassando pelos tons e pelas dores do processo escravocrata, da submissão, violência e marginalização dos negros. De forma sincrônica, o discurso é um apelo pela valorização das raízes da cultura negra, um resgate da identidade, um grito pela liberdade, pelo reconhecimento e respeito.

A seguir, é apresentado o corpus de análise do estudo.

Carta à Mãe África ${ }^{3}$

Genival Oliveira Gonçalves - GOG4 (com participação especial de Ellen Oléria) $)^{5}$

\footnotetext{
3 Letra da música disponível em: <https://www.letras.com.br/gog/carta-a-mae-africa $>$. Acesso em: 11 jan. 2020.

4 Página oficial do rapper Genival Oliveira Gonçalves (GOG): <www.gograpnacional.com.br>. Acesso em: 11 jan. 2020.

5 Vídeo da música "Carta à mãe África" com a interpretação de GOG e Ellen Oléria disponível em: $<$ https://youtu.be/C1Q1mtChWmE $>$. Acesso em: 11 jan. 2020 .
} 
É preciso ter pés firmes no chão

Sentir as forças vindas dos céus, da missão

Dos seios da mãe África e do coração

É hora de escrever entre a razão e a emoção

Mãe! Aqui crescemos subnutridos de amor

A distância de ti, o doloroso chicote do feitor

Nos tornou algo nunca imaginável, imprevisível

$\mathrm{E}$ isso nos trouxe um desconforto horrível

As trancas, as correntes, a prisão do corpo outrora

Evoluíram pra prisão da mente agora

Ser preto é moda, concorda? Mas só no visual

Continua caso raro ascensão social

Tudo igual, só que de maneira diferente

A trapaça mudou de cara, segue impunemente

As senzalas são as ante salas das delegacias

Corredores lotados por seus filhos e filhas

Hum! Verdadeiras ilhas, grandes naufrágios

A falsa abolição fez vários estragos

Fez acreditarem em racismo ao contrário

Num cenário de estações rumo ao calvário

Heróis brancos, destruidores de quilombos

Usurpadores de sonhos, seguem reinando

Mesmo separado de ti pelo Atlântico

Minha trilha são seus românticos cânticos

Mãe! Me imagino arrancado dos seus braços

Que não me viu nascer, nem meus primeiros passos

O esboço! É o que tenho na mente do teu rosto

Por aqui de ti falam muito pouco

E penso... Qual foi o erro cometido?

Por que fizeram com a gente isso?

O plano fica claro... É o nosso sumiço

O que querem os partidários, os visionários disso

Eis a questão

A maioria da população tem guetofobia

Anomalia sem vacinação

E o pior, a triste constatação 
Muitos irmãos patrocinam o vilão

De várias formas oportunistas, sem perceber

Pelo alimento, fome, sede de poder

$\mathrm{E}$ o que menos querem ser e parecer

Alguém que lembre, no visual, você

A carne mais barata do mercado é a negra

A carne mais marcada pelo Estado é a negra (refrão - 2x)

Ainda reconheço quem sou, e vou

Mesmo ferido, ao fronte, ao combate

Os tiros ouvidos aqui vêm de todos os lados

Mas não se pode seguir agachado

É por instinto que levanto o sangue Banto-Nagô

E em meio ao bombardeio

E em meio a fumaça, sigo sem nenhum disfarce

Pois minha face delata ao mundo o que quero

Voltar pra África, viver meus dias sem terno

Eterno! É o tempo atual, na moral

No mural vendem uma democracia racial

E os pretos, os negros, afrodescendentes

Passaram a ser obedientes, afroconvenientes

Nos jornais, entrevistas nas revistas

Alguns de nós, quando expõem seus pontos de vista

Tentam ser pacíficos, cordiais, amorosos

E eu penso como os dias tem sido dolorosos

E rancorosos, maldosos muitos são

Quando falamos numa mínima reparação

Ações afirmativas, inclusão, cotas?!

O opressor ameaça recalçar as botas

Nos mergulharam numa grande confusão

Racismo não existe e sim uma social exclusão

Mas sei fazer bem a diferenciação

Sofro pela cor, pelo patrão e o padrão

$\mathrm{E}$ a miscigenação, tema polêmico no gueto

Relação do branco, do índio com preto 
Fator que atrasou ainda mais a autoestima

-Tem cabelo liso, mas olha o nariz da menina

O espelho na favela após a novela é o divã

Onde os parceiro sonha em ser galã

Onde as garota viaja

Quer ser atriz ao em vez de meretriz

Onde a lágrima corre como num chafariz

Quem diz! Que este povo foi um dia unido

E que um plano o trouxe para um lugar desconhecido

Hoje amado (Ah! muito amado), são mais de quinhentos anos

Criamos nossos laços, reescrevemos sonhos

Mãe! Sou fruto do seu sangue, das suas entranhas

O sistema me marcou, mas não me arrebanha

O predador errou quando pensou que o amor estanca

Amo e sou amado no exílio por Dona Sebastiana

A carne mais barata do mercado é a negra

A carne mais marcada pelo Estado é a negra (refrão $2 \mathrm{x}$ )

Composição: Genival Oliveira Gonçalves - GOG (2006)

A partir das considerações teóricas arroladas e do corpus analítico do estudo, é possível ter uma compreensão de como o ethos pode funcionar como um movimento retórico com expressiva repercussão argumentativa no discurso. Em consonância com essa vertente, o enunciador do documento em análise apresenta um discurso por meio do qual podem ser percebidas outras vozes e interdiscursos correlacionados aos povos negros, que servem de sustentação para o seu posicionamento em defesa de valores como liberdade, igualdade e justiça, os quais ajudam a engendrar sua legitimidade e autoridade discursiva.

O ethos discursivo se manifesta pela entonação expressiva da denúncia, da luta e da resistência que o enunciador imprime ao enunciado no momento em que interage com o seu auditório. As marcas do ethos do enunciador podem ser depreendidas a partir de uma totalidade presente na materialidade discursiva de sua obra. Assim como Maingueneau (2008b) assevera, é interessante perceber que o discurso não se apresenta apenas como um conteúdo, mas também retrata um modo de dizer que vai 
construindo os sujeitos da enunciação (o enunciador/o enunciatário). Podese dizer que, nesse movimento, o enunciador de "Carta à mãe África" busca criar uma imagem que inspire confiança na audiência em correspondência com os princípios da Retórica Clássica - estabelece quase uma espécie de contrato fiduciário.

No discurso em análise, percebe-se a construção de um sujeito em busca de sua identidade, que transita entre dois expoentes que compõem sua essência sociocultural e histórica, trata-se, pois, de sua terra idealizada - África e de sua terra da experiência de vida - Brasil. A África consiste na fonte de sua identidade na esfera social, seu lócus de pertencimento, sua existência plena no mundo, onde ele percebe o reflexo de sua imagem como a projeção de sua real natureza. Já o Brasil simboliza, para esse sujeito, o exílio, o território da renúncia do eu, onde ele percebe a refração de sua imagem, onde a fragmentação de sua constituição sociocultural relega tanto a sua individualidade quanto a sua compleição coletiva.

Considerando tais aspectos, pode-se dizer que é um sujeito em estado de ambivalência, que experimenta, ao mesmo tempo, sentimentos opostos, os quais se interconectam pela atemporalidade dos tempos que os sustentam. Cabe destacar que a historicidade dos fatos que o sujeito aborda é parte de sua composição histórica. Nesse contexto, esse sujeito extravasa seu sentimento de cólera frente às situações indignas com sarcasmo, por meio de interpelações e cotejamentos pontuais, de forma a fomentar, na mente dos interlocutores, desenhos de cenários que mobilizem, simultaneamente, adesão (reciprocidade em relação) às suas verdades e aversão aos argumentos contrários às suas colocações.

Tomando "a carne" como manifesto, como dispositivo central da sua enunciação, o enunciador consegue projetar o eu poético no sentido de condicionar o auditório à sua regência discursiva. É pelo embate conformado no plano discursivo pautado na tênue trama da identificação e não-identificação sob a perspectiva da alusão ao "não útero" e ao "útero" que o enunciador imprime uma imagem que reverbera posturas de resistência e combatividade perante as condições e a realidade do racismo e a historicidade e as projeções da escravidão. Em decorrência dos posicionamentos do enunciador diante dessa contextualização, percebe-se a manifestação de um ethos do sujeito lutador sob o prisma da resiliência. 
Sobrevivente da marginalização, do reduto da violência ("Os tiros ouvidos aqui vêm de todos os lados"), de uma "guerra fria" condicionada pela contínua/operante escravidão ("Quando falamos numa mínima reparação/ Ações afirmativas, inclusão, cotas?!/ O opressor ameaça recalçar as botas"), do racismo (des)velado ("Racismo não existe e sim uma social exclusão/ Mas sei fazer bem a diferenciação/ Sofro pela cor, pelo patrão e o padrão"), dos pré-conceitos e dos preconceitos ("No mural vendem uma democracia racial/ E os pretos, os negros, afrodescendentes/ Passaram a ser obedientes, afroconvenientes"), o ethos do sujeito lutador que ecoa em "Carta à mãe África" não se constitui apenas no movimento da relutância mas, acentuadamente, em um posicionamento de combatividade atuante, nos moldes de uma militância, em prol da valorização da cultura negra, da reparação de direitos universais e da identidade e projeção do povo negro na sociedade.

Ao criar um campo de proposições discursivas que mobilizam contraposições argumentativas, o ethos discursivo clama pela igualdade, pelo respeito e pela visibilidade, buscando ressonância na esfera social o movimento de alteridade. Discursivamente, o lamento, a dor, a luta e a (re)ação percorrem pelo ethos do lutador de forma gradual e progressiva. A seleção lexical da composição musical confere ao discurso um tom de denúncia do racismo e da escravidão, fazendo emergir, na superfície discursiva, a imagem de um sujeito combatente e proativo perante os seus ideais e os dilemas a serem enfrentados e preocupado com a adesão a ser estabelecida com o seu auditório.

Nesse contexto e estado de resiliência, uma estratégia discursiva utilizada como mecanismo argumentativo de contraponto do ethos do lutador, a qual acaba fazendo com que ele se estruture e fortaleça no discurso, é justamente a forma como explora alguns operadores argumentativos, fazendo, sobretudo, com que as contraposições possam ser refletidas para que as realidades ora obscurecidas sejam evidenciadas. As sentenças subsequentes explicitam esse aspecto: "Ser preto é moda, concorda? Mas só no visual”; "Continua caso raro ascensão social/ Tudo igual, só que de maneira diferente"; "Os tiros ouvidos aqui vêm de todos os lados/ Mas não se pode seguir agachado"; "Racismo não existe e sim uma social exclusão/ Mas sei fazer bem a diferenciação"; “Tem cabelo liso, mas olha o nariz da menina"; "O sistema me marcou, mas não me arrebanha". 
Consequentemente, com esse movimento discursivo provoca réplicas e tréplicas contínuas, aspecto que dota de dinamismo o discurso e acaba despertando a atenção do auditório, sua responsividade e possível adesão aos efeitos de sentido produzidos.

O ethos do lutador busca o combate à opressão do Estado (partidários/ visionários), do branco (destruidores de quilombos/usurpadores de sonhos) e do próprio irmão, o qual não se reconhece como seu irmão, que se vende pelo poder, pela busca da sobrevivência ("muitos irmãos patrocinam o vilão"), sem se importar com as possíveis consequências ulteriores, como, por exemplo, o branqueamento da população negra, o genocídio da cultura negra. Esse ethos projetado pelo enunciador deixa marcas linguísticas e discursivas de que a libertação de seu povo perpassa pelo término do aprisionamento da mente, rompendo com ideias imputadas por outras culturas que reproduzem paradigmas que cerceiam a liberdade do negro - "Nos mergulharam numa grande confusão/ Racismo não existe e sim uma social exclusão/ Mas sei fazer bem a diferenciação/ Sofro pela cor, pelo patrão e o padrão".

A utilização de advérbios temporais e espaciais, como agora, hoje, outrora, aqui, retratam uma retrospectiva ao passado e um diálogo permanente com o presente, balizando o eixo argumentativo do discurso. São nesses deslocamentos realizados por meio dos advérbios que o ethos transita entre o passado e o presente, criando um campo de antíteses contínuo que auxilia no processo dialético entre essas duas dimensões e acaba contribuindo para arquitetar um discurso atemporal: "As trancas, as correntes, a prisão do corpo outrora/ Evoluíram pra prisão da mente agora"; "Mãe! Aqui crescemos subnutridos de amor/ A distância de ti, o doloroso chicote do feitor".

No discurso, a presença de índices de interatividade é bem expressiva, como por exemplo: o agenciamento da primeira pessoa do plural - "Alguns de nós, quando expõem seus pontos de vista/ Tentam ser pacíficos, cordiais, amorosos"; a utilização da primeira pessoa explicitando a inscrição do locutor no discurso - "Mãe! Me imagino arrancado dos seus braços" / "E eu penso como os dias tem sido dolorosos/ E rancorosos, maldosos muitos são"; o uso de interjeições que revelam ironia e apelo, clamor - "Hum! Verdadeiras ilhas, grandes naufrágios" / "Quem diz! Que este povo foi um dia unido" / "Mãe! Sou fruto do seu sangue, das suas 
entranhas"; o uso de interpelações que demonstram a busca por adesão "Ser preto é moda, concorda?" / "E penso... Qual foi o erro cometido?/ Por que fizeram com a gente isso?"; o emprego do tom de denúncia no discurso, que visa à reflexão e ao combate de mecanismos opressivos vinculados ao racismo e à escravidão - "A trapaça mudou de cara, segue impunemente/ As senzalas são a ante salas das delegacias/ Corredores lotados por seus filhos e filhas" / "Quando falamos numa mínima reparação/ Ações afirmativas, inclusão, cotas?! O opressor ameaça recalçar as botas".

No tecimento dessa trama argumentativa, percebe-se um ethos discursivo fruto da resiliência, que projeta seu discurso com ares de martírio, com vistas a externar suas dores e, em concomitância, a fortalecer seu clamor por mudanças no status quo da situação do negro no Brasil. Como estratégia argumentativa, esse sujeito problematiza as temáticas centrais de seu discurso instituindo, gradativamente, tomadas de consciência política e cidadã. Verifica-se, portanto, que a imagem construída e projetada do enunciador no/pelo discurso da música "Carta à mãe África" - o ethos discursivo - remete a um sujeito extremamente engajado na luta contra o racismo e a favor da representatividade e legitimidade da cultura e identidade negra.

\section{Considerações finais}

Compreende-se, no processo analítico aqui desencadeado, que a interdiscursividade é uma propriedade constitutiva do discurso. Significa, portanto, perceber e entender que o discurso é constituído de outros discursos - pelos já ditos e por outros a serem ainda produzidos, pois como Possenti (2002, p. 65) salienta, “[...] o discurso nunca é originário de um eu, mas de um outro (discurso)”. Isso porque “[...] as palavras nossas são também do outro e como tais estão carregadas dos murmúrios da história de seus empregos, das cargas dos tons avaliativos que carregaram e carregarão" (GERALDI, 2017, p. 55).

Dada a análise desenvolvida a respeito do discurso da música "Carta à mãe África", a atividade discursiva realizada pelo enunciador pode ser flagrada por meio da observação dos modos como se posiciona 
enunciativamente e da percepção e análise dos movimentos dialógicos, (inter)discursivos que articula, a fim de mobilizar o auditório e, sobretudo, de legitimar o seu discurso. Nesse trabalho do/no plano discursivo, o enunciador inscreveu e deixou entrever um ethos discursivo bem demarcado pelo conteúdo de sua enunciação e por meio de uma mobilização de estratégias argumentativas correspondente aos ideais basilares propostos pela composição musical.

No corpus em análise, a fim de explorar as temáticas centrais e as subtemáticas, o enunciador recorreu a processos de metaforização e jogos semióticos que desencadearam dicotomias, ora implícitas e explícitas no/pelo discurso, e a exemplificações e cotejamentos que propiciaram um dinâmico jogo antitético. Marcas de alteridade, atravessamento de formações discursivas que revelam/mobilizam o outro, foram exploradas na composição discursiva da música visando a promover o dialogismo entre o enunciador e o seu auditório.

O ethos discursivo construído, mobilizado e projetado sob o prisma da resiliência em "Carta à mãe África" se revelou na instância da enunciação, deixando marcas linguísticas e textuais na materialidade discursiva. Nesse percurso, foi posta em evidência a imagem de um sujeito em plena busca pela sua identidade, transitando entre dois expoentes constituintes de sua essência sociocultural e histórica - a terra idealizada (África) e a terra da experiência de vida (Brasil). Por meio do embate instaurado na materialidade discursiva, pautado na contraposição da identificação e da não-identificação sob a perspectiva da alusão ao não útero e ao útero, o enunciador imprimiu uma imagem que reverberou posturas de resistência e combatividade perante as condições e a realidade do racismo e a historicidade e as projeções da escravidão.

Sob essa perspectiva, pode-se dizer que o ethos discursivo do corpus funciona como um movimento retórico com expressiva repercussão argumentativa no discurso. Procedendo à análise, foi possível perceber que o enunciador construiu o ethos de um sujeito inscrito em um contexto sociopolítico e histórico bastante opressor à condição do negro na sociedade brasileira, que enuncia a partir de uma formação discursiva e ideológica pautada na busca pela valorização, pelo respeito e pela legitimidade da identidade e cultura negra. No tecido enunciativo, o enunciador buscou criar a imagem de um sujeito consciente da sua responsabilidade social - o 
ethos do lutador. O jogo persuasivo desencadeado com seu auditório foi sendo fortalecido por meio da construção, mobilização e projeção de sua imagem de luta e combatividade frente ao racismo e às condições que fazem reavivar a escravidão. Consoante a esses aspectos, foram sendo criados, concomitantemente, uma rede de adesão e um determinado movimento de conscientização sobre as causas em questão sob o prisma da resiliência.

\section{Referências}

AGUSTINI, C. L. H.; GRIGOLETTO, E. Escrita, Alteridade e Autoria em Análise do Discurso. Matraga, Rio de Janeiro, v. 15, n. 22, p. 145-156, jan./jun. 2008. Disponível em: <http://www.pgletras.uerj.br/matraga/ matraga22/arqs/matraga22a08.pdf $>$. Acesso em: 11 jan. 2020.

ARISTÓTELES. Retórica. São Paulo, SP: Folha de São Paulo, 2015. 238 p. (Coleção Folha; Grandes nomes do pensamento).

BAKHTIN, M. Estética da criação verbal. Tradução de Paulo Bezerra. 4. ed. São Paulo: Martins Fontes, 2003.

BAKHTIN, M. Marxismo e filosofia da linguagem. São Paulo: Hucitec, 2014.

BAKHTIN, M. Problemas da Poética de Dostoiévski. 3. ed. Tradução de Paulo Bezerra. Rio de Janeiro: Forense Universitária, 2002.

CARTA À MÃE ÁFRICA. Intérpretes: Ellen Oléria e Genival Oliveira Gonçalves (GOG). Compositor: Genival Oliveira Gonçalves (GOG). In: Aviso às gerações [CD]. Brasília: Só Balanço, 2006. 1 CD.

CARTA À MÃE ÁFRICA. Intérpretes: Ellen Oléria e Genival Oliveira Gonçalves (GOG). Compositor: Genival Oliveira Gonçalves (GOG). [Vídeo]. Disponível em: <https://youtu.be/C1Q1mtChWmE>. Acesso em: 11 jan. 2020.

COURTINE, J. O tecido da memória: algumas perspectivas de trabalho histórico nas ciências da linguagem. Polifonia, Cuiabá, Edufmt, v. 12, n. 
2, p. 1-13, 2006. Disponível em: <http://periodicoscientificos.ufmt.br/ojs/ index.php/polifonia/article/view/1067/840>. Acesso em: 11 jan. 2020.

FOUCAULT, M. A ordem do discurso. 3. ed. São Paulo: Loyola, 1996.

GERALDI, J. W. Perspectivas críticas dos estudos da linguagem do Círculo de Bakhtin. In: FERREIRA, R.; RAJAGOPALAN, K. (org.). Um mapa da crítica dos estudos da linguagem e do discurso. Campinas: Pontes, 2017. p. 33-62.

GOLDSTEIN, T. S. Entre o conceito e a metáfora: a resiliência como abordagem do humano a partir da física dos materiais. Mundo da Saúde, São Paulo, v. 36, n. 2, p. 327-331, 2012. Disponível em: <https://scholar. google.com/scholar_lookup? >. Acesso em: 11 jan. 2020.

GROTBERG, E. Aguide to promoting resilience in children: strengthening the human spirit. The Hague: The Bernard van Leer Foundation, 1995.

INDURSKY, F. A memória na cena do discurso. In: INDURSKY, F; MITTMAN, S; FERREIRA, M. C. L. Memória e história na/da análise do discurso. Campinas, SP: Mercado de Letras, 2011. p. 67-89.

INDURSKY, F. As determinações da prática discursiva da escrita. Revista Desenredo do Programa de Pós-graduação em Letras da Universidade de Passo Fundo, Passo Fundo, v. 12, n. 1, p. 30-47, jan./jul. 2016. Disponível em: <http://seer.upf.br/index.php/rd/article/view/5954/3898>. Acesso em: 11 jan. 2020.

MAINGUENEAU, D. A propósito do ethos. Tradução de Luciana Salgado. In: MOTTA, A. R.; SALGADO, L. (org.). Ethos discursivo. São Paulo: Contexto, 2008a. p. 11-29. Disponível em: $<$ https://pt.scribd.com/ document/166478968/Maingueneau-D-A-proposito-do-ethos $>$. Acesso em: 11 jan. 2020.

MAINGUENEAU, D. Cenas da enunciação. São Paulo: Parábola Editorial, 2008b.

POSSENTI, S. Os limites do discurso: ensaios sobre discurso e sujeito. Curitiba: Edições Criar, 2002. p. 61-73. 